\title{
APPLICATION OF BINARY VERSION GSA FOR SHUNT CAPACITOR PLACEMENT IN RADIAL DISTRIBUTION SYSTEM
}

\author{
Nasim Ali Khan ${ }^{1}$, S. Ghosh ${ }^{2}$, Sandeep S. R ${ }^{3}$, SalimMondal ${ }^{4}$ \\ ${ }^{1}$ Assistant Professor, Aliah University \\ ${ }^{2}$ Professor, NIT Durgapur; \\ ${ }^{3}$ Assistant Professor, SJBIT, Bangalore \\ ${ }^{4} P G$ Student,Aliah University
}

\begin{abstract}
This paper presents a binary gravitational search algorithm (BGSA) is applied to solve the problem of optimal allotment of Shunt capacitors in radial distribution systems. In this work, total line loss (TLL) and the total voltage deviations (TVD) are to be minimized separately by incorporating optimal placement of shunt capacitors with constraints which include limits on voltage, sizes of installed capacitors. This BGSA is applied on the balanced IEEE 12-Bus distribution network and the results are compared with conventional binary particle swarm optimization (BPSO).
\end{abstract}

\section{INTRODUCTION}

It has been seen that as much as $13 \%$ of total power generated is wasted in the form of losses at the distribution level [1]. Grainger and Lee [2] developed a nonlinear programming based method in which capacitor location and capacity were expressed as continuous variables. Baran and $\mathrm{Wu}$ [3] distinguished capacitor placement problem separately into a master problem and a slave problem. The master problem was used to determine the location of the capacitors while the slave problem was used to determine the type and size of the capacitors. Chen et al. [4] considered the mutual coupling effect of conductors to install capacitors in unbalanced distribution systems. Duran et al. [5] considered the capacitor sizes as discrete variables and employed dynamic programming to solve the problem. Schmill [6] developed well-known two-third rule for the placement of one capacitor assuming a uniform load and a uniform distribution feeder. Grainger et al. [7] formulated the capacitor placement and voltage regulator problem and proposed decoupled solution methodology for general distribution system. Placement and sizing of shunt capacitors by using loss sensitivity factors and plant growth simulation algorithm were done in Raoet al [8]. The loss sensitivity factor was used to predict which bus has the largest loss reduction when a capacitor was placed. S. G. Saranyaet al. [9] employed fuzzy expert system (FES) method for determining suitable candidate nodes in distribution systems for capacitor installation. Recently, Rashediet al. [10] proposed a new optimization algorithm called Gravitational Search Algorithm (GSA), which has been demonstrated to be very interesting to find solutions of unimodal and multimodal functions. GSA is based on the law of attraction of masses supported by the Newtonian gravity, which says that "a particle in the universe attracts every other one with a force that is directly proportional to the product of their masses and inversely proportional to the square of the distance between them". The original version of GSA was designed for search spaces of real valued vectors. However, many optimization problems are set in binary discrete space, such as feature selection and data mining [11] dimensionality reduction [1216], unit commitment [17], and cell formation [18], in which it is natural to encode solutions as binary vectors. In addition, problems defined in the real space, may be considered in the binary space, too. The solution is to display real digits with some bits in the binary mode. The binary search space is considered as a hypercube in which an agent may move to nearer and farther corners of the hypercube by flipping various numbers of the bits. In the literatures, very few papers use the optimization of voltage profile as objective functions. In this work, a binary version of GSA (BGSA) [19] is utilized to decide the optimal locations of shunt capacitors to obtain an overall better voltage profile for a radial distribution system. In the BGSA, the outcome of these forces is converted into a probability value for each element of the binary vector, which guides whether that elements will take on the value 0 or 1 . The objective function is to minimize total line loss (TLL) and maximize the lowest voltage level of the system i.e., nothing but minimize total voltage deviation (TVD) to reach a better voltage profile. The locations of capacitors are formulated by binary variables as decision variables in the constraints.

\section{POWER FLOW SOLUTION IN RADIAL DISTRIBUTION SYSTEM}

The load flow solution is carried by the following set of recursive equations (1) and (2) derived from the single line diagram as shown in Fig. 1. 


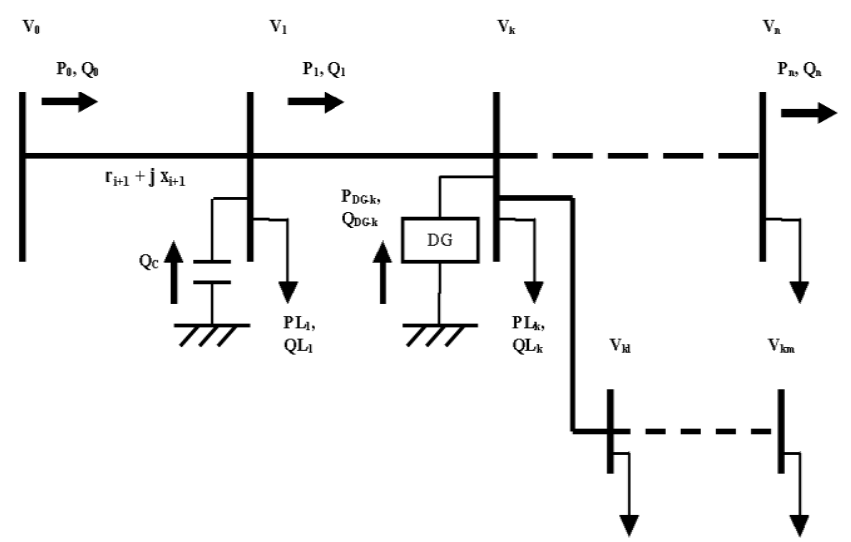

Fig. 1: Single line diagram of a Radial distribution system

$$
\begin{aligned}
& P_{i+1}=P_{i}-P_{L i+1}-R_{i, i+1} \cdot\left(\frac{P_{i}^{2}+Q_{i}^{2}}{\left|V_{i}\right|^{2}}\right) \\
& Q_{i+1}=Q_{i}-Q_{L i+1}-X_{i, i+1} \cdot\left(\frac{P_{i}^{2}+Q_{i}^{2}}{\left|V_{i}\right|^{2}}\right)
\end{aligned}
$$

Where $P_{\mathrm{i}}$ is the real power flow into the sending end of branch $i+l$ connecting bus $i$ and bus $i+1 ; \quad P_{L i+1}$ is real component of load at bus $i+1 ; R_{i, i+1}$ is the resistance of line section between buses $i$ and $i+1$ and $V_{\mathrm{i}}$ is the bus voltage magnitude at bus ${ }_{\mathrm{i}}$. $Q_{i}$ is the reactive power flow into the sending end of branch $i+1$ connecting bus $i$ and bus $i+1 ; Q_{L i+}$ ${ }_{l}$ is reactive component of load at bus $i+1 ; X_{i, i+l}$ is the reactance of line section between buses $i$ and $i+1$.

The problem of capacitor allotment with their proper capacities is of great importance. The installation of shunt capacitors at non-optimal places can result in an increase in system losses, voltage deviations and costs. Therefore, a power system planning engineer requires an efficient and fast optimization method capable of indicating the best solution for a given distribution network. The selection of the best places for installation and the preferable sizes of the shunt capacitor banks in large distribution systems is a complex discrete optimization problem. In order to incorporate the proposed method recursive equations (1) and (2) are modified as follows:

\subsection{Real Power Flow with Installation of Shunt}

\section{Capacitor}

$$
P_{i+1}=P_{i}-P_{L i+1}-R_{i, i+1} \cdot\left(\frac{P_{i}^{2}+Q_{i}^{2}}{\left|V_{i}\right|^{2}}\right)+A P_{i+1} \cdot \mu P
$$

Where $A P_{\mathrm{i}+1}$ is shunt capacitor active power magnitude injected at bus $i+1 ; \mu P$ is shunt capacitor power multiplier, set to zero when there is no shunt capacitor power source or set to 1 when there is active power source.

\subsection{Reactive Power Flow with Shunt Capacitor}

\section{Placement}

$$
Q_{i+1}=Q_{i}-Q_{L i+1}-X_{i, i+1} \cdot\left(\frac{P_{i}^{2}+Q_{i}^{2}}{\left|V_{i}\right|^{2}}\right)+R P_{i+1} \cdot \mu Q^{(4)}
$$

Where $R P_{\mathrm{i}+1}$ is shunt capacitor reactive power magnitude injected at bus $i+1 ; \mu Q$ is Shunt capacitor power multiplier, set to zero when there is no capacitor power source or set to 1 when there is a capacitor power source.

\subsection{Computation of Bus Voltages}

$$
\begin{aligned}
V_{i+1}{ }^{2} & =V_{i}^{2}-2\left(R_{i, i+1} \cdot P_{i}+X_{i, i+1} \cdot Q_{i}\right)+\left(R_{i, i+1}{ }^{2}+X_{i, i+1}{ }^{2}\right) . \\
& \frac{P_{i}^{2}+Q_{i}^{2}}{\left|V_{i}\right|^{2}}
\end{aligned}
$$

\section{PROBLEM FORMULATION}

The following sections describe the details of the proposed problem formulation.

\subsection{The Objective Functions}

The main advantages of Shunt capacitors in the distribution system are loss minimization in the feeders and the improvement in the voltage profile, i.e. maintaining the voltages at customer terminals with reactive power compensation. The following functions are computed using the proposed algorithm: Total Line Loss (TLL), Total Voltage Deviation (TVD).

\subsection{Total Line Loss (TLL)}

The installation capacitor banks should not result in an increase in the system losses. The power loss of the line section connecting buses $i$ and $i+1$ is computed as:

$P_{\text {loss }}(i, i+1)=R_{i, i+1} * \frac{P_{i}^{2}+Q_{i}^{2}}{\left|V_{i}\right|^{2}}$

$T L L=\sum_{i}^{n-1} P_{\text {loss }}(i, i+1)$

\subsection{Total Voltage Deviation (TVD)}

Voltage deviation can also be minimized with integration of Shunt capacitors. The total voltage deviation (TVD) in the system, which is to be minimized, is expressed as:

$$
T V D=\sum_{i 1}^{n-1}\left|1-V_{i}\right|
$$

Where $\mathrm{i}=1,2,3 \ldots \ldots \ldots$ and $V_{i}$ is the voltage of $\mathrm{i}^{\text {th }}$ bus in per unit for the system buses; the ideal magnitude of each bus voltage is unity. 


\subsection{Constraints}

The following constraints are considered [20].

\section{i) Total Power Conservation:}

The algebraic summation of all incoming and outgoing powers over the feeders, taking into consideration the feeders' losses and the powers supplied by Shunt capacitors should be equal to the total demand at that bus.

ii) Distribution Feeder's Thermal Capacity:

Power flows in feeders must be within their capacities.

\section{iii) Distribution Substation's Capacity:}

The summation of total powers delivered to the network by the substation's transformers must be within the substation's capacity limit.

\section{iv) Shunt capacitor Operation Limits:}

The Shunt capacitor's generated power must be within the Shunt capacitor's capacity.

\section{v) Voltage Drop Limits:}

The voltage levels at different buses must be within predetermined values.

\section{PROPOSED BINARY GRAVITATIONAL SEARCH ALGORITHM}

The conventional GSA was originally designed to solve problems in continuous valued space [6]. The search algorithm is based on the metaphor of gravitational interaction between masses in the Newton theory. $\mathrm{A}^{\text {th }}$ bit of the $\mathrm{i}^{\text {th }}$ agent $\left(x_{i j}\right)$ in a system is represented as a bit 0 or 1 where a combination of bits gives the $\mathrm{i}^{\text {th }}$ agent position.

The next agent's velocity $\left(v_{i j}\right)$ is calculated based on its current velocity and its acceleration as expressed in (9). Then, a new agent's position $\left(x_{i j}\right)$ is updated using a condition as shown in (11). However, the velocity is limited in interval $[-6,6]$ so as to achieve a good convergence rate.

$$
\begin{gathered}
v_{i j}(t+1)=r^{*} v_{i j}(t)+a_{i j}(t) \\
\text { Sigmoid }\left(v_{i}{ }^{d}\right)=\frac{1}{1+e^{-v_{i}{ }^{d}}} \\
x_{i}{ }^{d}=\left\{\begin{array}{c}
0, \text { if } r>=\operatorname{sigmoid}\left(v_{i}{ }^{d}\right) \\
1, \text { otherwise }
\end{array}\right.
\end{gathered}
$$

\section{SIMULATION RESULTS AND DISCUSSION}

To demonstrate the performance of the proposed BGSA in solving the optimal shunt capacitor placement problem, the IEEE 12-bus distribution system is used in this study. In this paper, for this test system, TLL and TVD were minimized and compared to the conventional BPSO as to illustrate its performance in solving the same problem. All the optimization parameters are standardized where population size and maximum population are set to 60 and 100, respectively. In the BPSO, two positive coefficients are set to $2(c 1=c 2=2)$ and inertia weight, $(w)$ monotonously decreases from $0.9\left(w_{\max }\right)$ to $0.4\left(w_{\min }\right)$. In the BGSA, the initial gravity constant, G0 is set to 100 and the best applying force, $\left(K_{\text {best }}\right)$ is monotonously decreased from $100 \%\left(K_{\text {bestmax }}\right)$ to $2.5 \%\left(K_{\text {bestmin }}\right)$. The proposed BGSA algorithm has been implemented on IEEE 12-bus radial distribution network.

IEEE 12-Bus [21] has single line main feeder (Base Voltage $=11 \mathrm{KV}$, Base MVA = $0.1 \mathrm{MVA}$ ) without laterals and sublaterals and having total active and reactive powers of 435 $\mathrm{kW}$ and $81 \mathrm{kVAR}$, respectively. Without any injection of shunt capacitors' reactive powers, the normal power flow (NPF) yields Total Line Loss (TLL) and total voltage deviation (TVD) as $20.7138 \mathrm{~kW}$ and 0.4020 p.u. respectively.

\subsection{Total Line Loss (TLL) Minimization}

With no constraints on the total capacities of Shunt capacitors, convergence characteristics of lossminimization and voltageprofile obtained by different algorithms are depicted in Fig. 2(a) and 2(b) respectively. It is observed from Table 3, voltage profile is improved as that of BPSO, and lowest bus voltage increased $1.02 \%$ by BPSO whereas in Binary GSA, it is improved by $2.17 \%$. In TLL minimization, TLL is reduced from $20.7138 \mathrm{~kW}$ to $12.2455 \mathrm{~kW}$ in case of BGSA, where as in BPSO it reduces to $17.7354 \mathrm{~kW}$ only and TVD is minimized from 0.4020 p.u. to 0.1993 p.u. and 0.2353 p.u. by BGSA and BPSO, respectively with injection of optimal placement of Shunt capacitors, as indicated in Table 1. From Table 4, it is observed three Shunt capacitors, each of $25 \mathrm{kVAR}$ capacity, equivalent to total $75 \mathrm{kVAR}$, are optimally placed for TLL minimization in BGSA approach but, in BPSO, total capacities of shunt capacitors is seems to be more.

\subsection{Total Voltage Deviation (TVD) Minimization}

Fig. 2(a) represents voltage profile of IEEE 12-bus radial distribution system obtained by optimization techniques (BPSO, BGSA) and normal power flow (NPF). It can be seen that voltage profile is improved as that of BPSO, lowest bus voltage increased $1.13 \%$ by BPSO whereas in Binary GSA, it is improved by $2.15 \%$, as seen from Table 3 . Convergence characteristic of TVD minimization is shown in Fig. 3(b). It can be found from Table 5, three Shunt Capacitors (at $2^{\text {nd }}, 3^{\text {rd }}$ and $8^{\text {th }}$ bus position), each of $25 \mathrm{kVAR}$ capacity, are equivalent to total $75 \mathrm{KVAR}$ optimally placed in BGSA. Some more capacity of Shunt capacitors is used in BPSO technique for TVD minimization. 


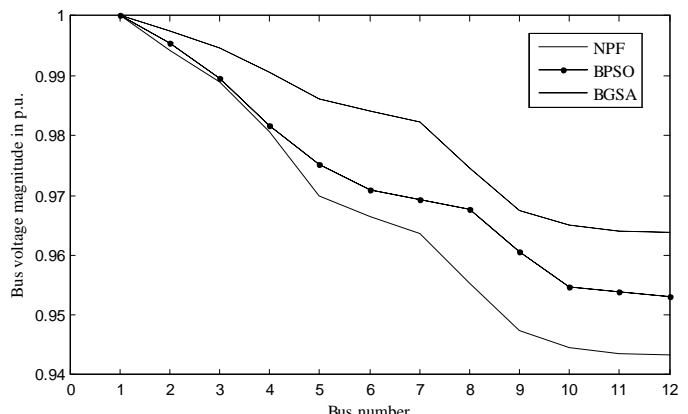

(a)

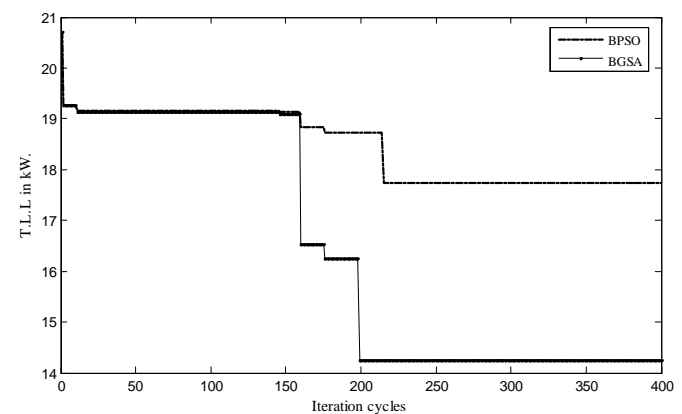

(b)

Fig. 2: TLL Minimization Characteristics of IEEE 12 Bus Radial Distribution System; (a) Voltage profile obtained by different algorithms, (b) Convergence characteristics

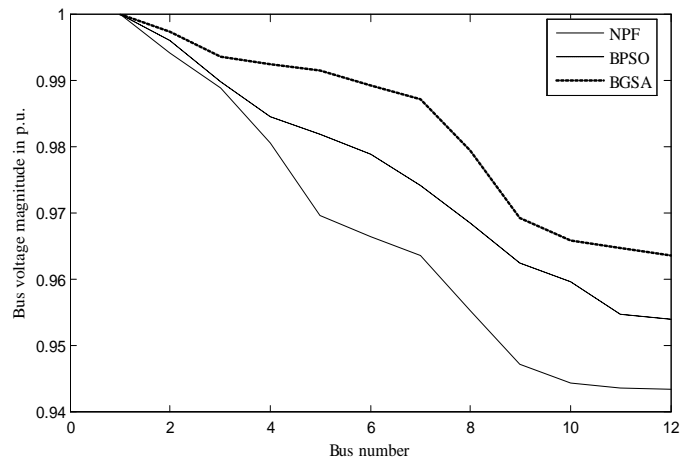

(a)

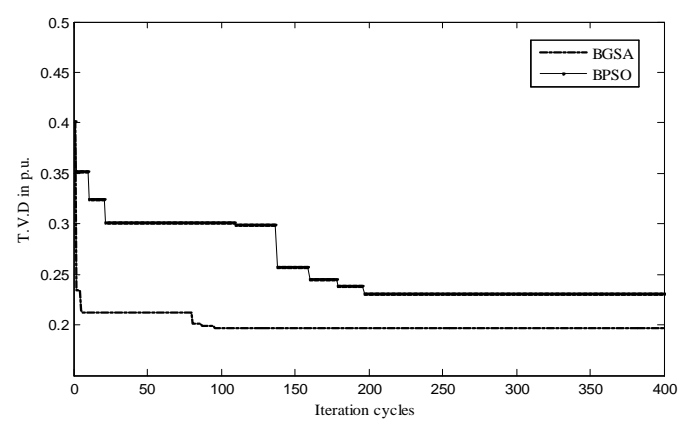

(b)

Fig. 3: TVD Minimization Characteristics of IEEE 12 Bus Radial Distribution System; (a) Voltage profile obtained by different algorithms, (b) Convergence characteristics.

\section{CONCLUSION}

This paper presented a BGSA and a comparative performance of BGSA and BPSO in solving the two separate single-objective optimization problem for optimal Shunt capacitor placement in IEEE radial distribution test system. The optimization techniques have been tested on this distribution test system for determining the best optimal Shunt capacitor placements for TLL and TVD minimization. The comparative results showed that the proposed BGSA is the most effective and precise among the aforementioned optimization techniques. In conclusion, the authors' contribution in this work is successful application of a binary GSA algorithm for simultaneous solution of optimal number and placements of Shunt capacitors in a balanced distribution system.

\section{REFERENCES}

[1] Y. H. Song, G. S. Wang, A. T. Johns and P. Y. Wang, "Distribution Network Reconfiguration for Loss Reduction using Fuzzy Controlled Evolutionary Programming", IEE Proc. Generation, Transmission and Distribution, 1997, 144(4), pp. 345-350.

[2] J. J. Grainger and S. H. Lee, "Optimum Size and Location of Shunt Capacitors for Reduction of Losses on Distribution Feeders", IEEE Trans. on Power Apparatus and Systems, 1981, vol. 100, no. 3, pp. 1105-1118.

[3] M. Baran and F. Wu, "Optimal capacitor placement on radial distribution system", IEEE Trans. on Power Delivery, 1989, 4(1), pp.725-734.

[4] C. S. Chen, C. T. Hsu and Y. Yan, "Optimal distribution feeder capacitor placement considering mutual coupling effect of conductors", IEEE Trans. on Power Delivery, 1995, 10(2), pp.987-94.

[5] H. Duran, "Optimum Number Size of Shunt Capacitors in Radial Distribution Feeders: A Dynamic Programming Approach", IEEE Trans. on Power Apparatus and Systems, 1968, 87, pp.1764-1774.

[6] J. V. Schmill, "Optimum Size and Location of Shunt Capacitors on Distribution Feeders", IEEE Trans. on Power Apparatus and Systems, 1965, 84, pp. 825-832.

[7] J. J. Grainger and S. Civanlar, "Volt/var control on Distribution systems with lateral branches using shunt capacitors as Voltage regulators Part I, II and III", IEEE Trans. on Power Apparatus and systems, 1985, vol.104, no.11, pp. 3278-3297.

[8] A. Swarnkar, N. Gupta and K. R Niazi, "Optimal Placement of Fixed and Switched Shunt Capacitors for Large- Scale Distribution Systems using Genetic Algorithms", Innovative Smart Grid Technologies Conference, 2010, pp.1- 8.

[9] S. G. Saranya, E. Muthukumaran, S. M. Kannan and S. Kalyani, "Optimal Capacitor Placement in Radial Distribution Feeders Using Fuzzy-Differential Evolution", Proceedings of the National Conference on Innovations in Emerging Technology, 2011, pp. 85-90.

[10] C. S. Chen, C. T. Hsu and Y. Yan, Optimal distribution feeder capacitor placement considering 
mutual coupling effect of conductors", IEEE Trans. on Power Delivery, 1995, 10(2), pp. 987-94.

[11] K. G. Srinivasa and K. R. Venugopal, "A self-adaptive migration model genetic algorithm for data mining applications", InfSci, 2007, 177(20), pp. 4295-4313.

[12] P. Avishek and J. Maiti, "Development of a hybrid methodology for dimensionality reduction in Mahalanobis-Taguchi system using Mahalanobis distance and binary particle swarm optimization", Expert System Applications, 2010, 37(2), pp.12861293.

[13] M. Beretaa and T. Burczynski, "Comparing binary and real-valued coding in hybrid immune algorithm for feature selection and classification of ECG signals", Engineering Applications of Artificial Intelligence, 2007, 20, pp. 571-585.

[14] X. Wang and J. Yang, "Feature selection based on rough sets and particle swarm optimization", Pattern Recognition Letter, 2007, 28, pp. 459-471.

[15] L. H. Chuang and H. W. Chang, "Improved binary PSO for feature selection using gene expression data, Computational Biological Chemistry, 2008, 32(1), pp. 29-38.
[16] X. P. Zeng and Y. M. Li, “A dynamic chain-like agent genetic algorithm for global numerical optimization and feature selection", Neuro-computing, 2009, 72, pp. 1214-1228.

[17] X. Yuan and A. Nie, "An improved binary particle swarm optimization for unit commitment problem", Expert Systems Application, 2009, 36(4), pp.80498055.

[18] T. H. Wu and C. C. Chang, "A simulated annealing algorithm for manufacturing cell formation problems", Expert Systems Application, 2008, 34(3), pp.16091617.

[19] E. Rashedi, H. Nezamabadi-pour and S. Saryazdi, "BGSA: binary gravitational search algorithm," Natural Computing, 2010, vol. 9, pp. 727-745.

[20] R. Annaluru, S. Das and A. Pahwa, "Multi-level ant colony algorithm for optimal placement of capacitors in distribution systems", Congress on Evolutionary Computation, 2004, Vol. 2, pp. 1932- 1937.

[21] D. Das, H. S. Nagi and D. P. Kothari, "Novel Method for Solving Radial Distribution Networks", IEE Proc. C, 1994, Vol. 141, (4), pp. 291-298.

Table 1: Comparative Study Of TLL Minimization Ieee 12-Bus Test System

\begin{tabular}{|l|l|l|l|l|l|}
\hline Test System & $\begin{array}{l}\text { NPF } \\
(\mathrm{kW})\end{array}$ & $\begin{array}{l}\text { BPSO } \\
(\mathrm{kW})\end{array}$ & $\begin{array}{l}\text { \% Improvement in } \\
\text { BPSO over NPF }\end{array}$ & $\begin{array}{l}\text { BGSA } \\
(\mathrm{kW})\end{array}$ & $\begin{array}{l}\text { \% Improvement in } \\
\text { BGSA over NPF }\end{array}$ \\
\hline EEE 12-Bus & 20.7138 & 17.7354 & 14.37 & 14.2455 & 31.22 \\
\hline
\end{tabular}

Table 2: Comparative Study Of TVD Minimization Ieee 12-Bus Test System

\begin{tabular}{|l|l|l|l|l|l|}
\hline Test System & $\begin{array}{l}\text { NPF } \\
\text { (p.u.) }\end{array}$ & $\begin{array}{l}\text { BPSO } \\
\text { (p.u.) }\end{array}$ & $\begin{array}{l}\text { \% Improvement in } \\
\text { BPSO over NPF }\end{array}$ & $\begin{array}{l}\text { BGSA } \\
\text { (p.u.) }\end{array}$ & $\begin{array}{l}\text { Improvement in } \\
\text { BCAB over NPF }\end{array}$ \\
\hline IEEE 12-Bus & 0.4020 & 0.2312 & 42.48 & 0.1963 & 51.16 \\
\hline
\end{tabular}

Table 3: Comparative Study Of Lowest Bus Voltage Improvement in Tll and TvdMinimization Ieee 12-Bus Test System

\begin{tabular}{|c|c|c|c|c|c|c|c|c|c|}
\hline \multirow{2}{*}{$\begin{array}{l}\text { Test } \\
\text { System }\end{array}$} & \multicolumn{5}{|c|}{ TLL Minimization } & \multicolumn{4}{|c|}{ TVD Minimization } \\
\hline & $\begin{array}{l}\text { NPF } \\
\text { (p.u. } \\
\text { ) }\end{array}$ & $\begin{array}{l}\text { BPSO } \\
\text { (p.u.) }\end{array}$ & $\begin{array}{l}\text { \% Improvement } \\
\text { in BPSO over } \\
\text { NPF }\end{array}$ & $\begin{array}{l}\text { BGS } \\
\text { A } \\
\text { (p.u.) }\end{array}$ & $\begin{array}{l}\text { \% Improvement } \\
\text { in BGSA over } \\
\mathrm{NPF}\end{array}$ & $\begin{array}{l}\text { BPSO } \\
\text { (p.u.) }\end{array}$ & $\begin{array}{l}\text { \% Improvement } \\
\text { in BPSO over } \\
\mathrm{NPF}\end{array}$ & $\begin{array}{l}\text { BGS } \\
\text { A } \\
\text { (p.u.) }\end{array}$ & $\begin{array}{l}\% \text { Improvement } \\
\text { in BGSA over } \\
\text { NPF }\end{array}$ \\
\hline $\begin{array}{l}\text { IEEE 12- } \\
\text { Bus }\end{array}$ & $\begin{array}{l}.943 \\
4\end{array}$ & .9531 & 1.02 & .9639 & 2.17 & .9541 & 1.13 & .9637 & 2.15 \\
\hline
\end{tabular}

Table 4: Optimal Locations Of Shunt capacitors for TLL Minimization Ieee 12-Bus Test System

\begin{tabular}{|c|c|c|c|c|}
\hline \multirow[b]{2}{*}{ Test System } & \multicolumn{2}{|l|}{ BPSO } & \multicolumn{2}{|l|}{ BGSA } \\
\hline & $\begin{array}{l}\text { Shunt } \\
\text { Capacitors } \\
\text { (kVAR) }\end{array}$ & $\begin{array}{l}\text { Optimal locations of shunt } \\
\text { capacitors }\end{array}$ & $\begin{array}{l}\text { Shunt Capacitors } \\
\text { (kVAR) }\end{array}$ & $\begin{array}{l}\text { Optimal locations of shunt } \\
\text { capacitors }\end{array}$ \\
\hline IEEE 12-Bus & 100 & $\begin{array}{llll}{[2,4,5,7],} & \text { each } & \text { capacitor of } \\
25 \mathrm{kVAR} & & & \end{array}$ & 75 & $\begin{array}{l}{[2,3,5], \text { each } \quad \text { capacitor }} \\
\text { 25kVAR }\end{array}$ \\
\hline
\end{tabular}

Table 5: Optimal Locations Of Shunt capacitors for Tvd Minimization Ieee 12-Bus Test System

\begin{tabular}{|c|c|c|c|c|}
\hline \multirow[b]{2}{*}{ Test System } & \multicolumn{2}{|l|}{ BPSO } & \multicolumn{2}{|l|}{ BGSA } \\
\hline & $\begin{array}{l}\text { Shunt } \\
\text { Capacitors } \\
\text { (kVAR) }\end{array}$ & $\begin{array}{l}\text { Optimal locations of shunt } \\
\text { capacitors }\end{array}$ & $\begin{array}{l}\text { Shunt Capacitors } \\
\text { (kVAR) }\end{array}$ & $\begin{array}{l}\text { Optimal locations of shunt } \\
\text { capacitors }\end{array}$ \\
\hline IEEE 12-Bus & 100 & $\begin{array}{llll}{[2,4,5,7],} & \text { each } & \text { capacitor } & \text { of } \\
25 \mathrm{kVAR} & & & \\
\end{array}$ & 75 & 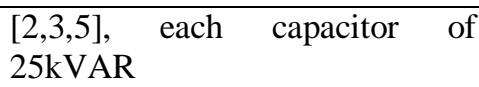 \\
\hline
\end{tabular}

